\title{
Tamoxifen Inhibits Mitochondrial Membrane Damage Caused by Disulfiram
}

\begin{tabular}{|c|c|}
\hline Journal: & Biochemistry and Cell Biology \\
\hline Manuscript ID & bcb-2017-0027.R1 \\
\hline Manuscript Type: & Article \\
\hline Date Submitted by the Author: & 15-May-2017 \\
\hline Complete List of Authors: & $\begin{array}{l}\text { Pavon, Natalia; Instituto Nacional de Cardiologia, Pharmacoloy } \\
\text { Buelna-Chontal, Mabel; Instituto Nacional de Cardiologia, Biomedicina } \\
\text { Cardiovascular } \\
\text { Correa, Francisco; Instituto Nacional de Cardiologia Ignacio Chavez, } \\
\text { Biomedicina Cardiovascular } \\
\text { Yoval-Sánchez, Belem; Instituto Nacional de Cardiologia Ignacio Chavez, } \\
\text { Bioquimica } \\
\text { Belmont, Javier; Instituto Nacional de Cardiologia, Bioquimica } \\
\text { Hernández-Esquivel, Luz; Instituto Nacional de Cardiologia Ignacio Chavez, } \\
\text { Bioquimica } \\
\text { Rodríguez-Zavala, Jose; Instituto Nacional de Cardiologia Ignacio Chavez, } \\
\text { Bioquímica } \\
\text { Chavez, Edmundo; Instituto Nacional de Cardiologia, Bioquimica }\end{array}$ \\
\hline $\begin{array}{r}\text { Is the invited manuscript for } \\
\text { consideration in a Special } \\
\text { Issue? : }\end{array}$ & $\mathrm{N} / \mathrm{A}$ \\
\hline Keyword: & $\begin{array}{l}\text { Disulfiram, Mitochondria, Tamoxifen, Oxidative stress, Permeability } \\
\text { transition }\end{array}$ \\
\hline
\end{tabular}




\title{
Tamoxifen Inhibits Mitochondrial Membrane Damage Caused by Disulfiram
}

\author{
Natalia Pavón ${ }^{1}$, Mabel Buelna-Chontal ${ }^{2}$, Francisco Correa ${ }^{2}$, Belem \\ Yoval-Sánchez ${ }^{3}$, Javier Belmont ${ }^{3}$, Luz Hernández-Esquivel ${ }^{3}$, José S. \\ Rodríguez-Zavala ${ }^{3}$, Edmundo Chávez $^{3}$ \\ ${ }^{1}$ Departamento de Farmacología, ${ }^{2}$ Departamento de Biomedicina \\ Cardiovascular, ${ }^{3}$ Departamento de Bioquímica. \\ Instituto Nacional de Cardiología, Ignacio Chávez, México.
}

Running Title: Tamoxifen inhibits mitochondrial leakiness induced by disulfiram

Corresponding author: Edmundo Chávez

Departamento de Bioquímica, Instituto Nacional de Cardiología “Ignacio Chávez" Juan Badiano Núm. 1 Tlalpan México D.F. CP 14080 echavez@salud.gov.mx 


\section{ABSTRACT}

In this work, we studied the protective effect of tamoxifen on disulfiraminduced mitochondrial membrane insult. The results indicate that tamoxifen circumvents inner membrane leakiness manifested by $\mathrm{Ca}^{2+}$ release, mitochondrial swelling, and collapse of the transmembrane electric gradient. Furthermore, it was found that tamoxifen prevents the inactivation of the mitochondrial enzyme aconitase and detachment of cytochrome c from the inner membrane. Interestingly, tamoxifen also inhibited disulfiram-promoted generation of hydrogen peroxide. Given that tamoxifen is an antioxidant molecule, it is plausible that its protection may be due to the inhibition of disulfiram-induced oxidative stress.

Key words: disulfiram, mitochondria, tamoxifen, oxidative stress 


\section{INTRODUCTION}

Disulfiram (Dis) is a drug occasionally used in the treatment of alcoholism, as well as in the treatment of human cancer cells (Tawari et al., 2015; Santos et al., 2016). However, the administration of Dis is not exempt of risks, and it eventually provokes harmful effects on health, e. g., heart injury (Amuchastegui et al., 2014), and hepatotoxicity (Watts et al., 2014). Actually, it is widely recognized that Dis induces oxidative stress. For example, Grosicka-Macsiag et al. (2010) have reported that in Chinese hamster fibroblasts, Dis at a concentration of up to $200 \mu \mathrm{M}$ promotes an increase of lipid peroxidation and an elevated carbonylated protein content. Cen et al. (2002) have observed that Dis at a dose of $25-40 \mathrm{ng} / \mathrm{ml}$ causes a significant increase in apoptosis on melanoma cells in vitro, through a mechanism in which oxidative stress is involved. In turn, Dogterom et al. (1989) reported that Dis induced the depletion of thiols and death in isolated rat hepatocytes, and that these effects are prevented by vitamin E. In fact, we reported in previous work that disulfiram promotes mitochondrial permeability transition (Chávez et al., 1989) inducing a complete loss of accumulated $\mathrm{Ca}^{2+}$, which is accompanied by a collapse of the transmembrane potential. 
Mitochondrial harm likely occurs through the opening of a $\mathrm{Ca}^{2+}$ overloaddependent transmembrane pore, which allows the release of matrix molecules with molecular weights of up to 1500 Da (Crompton et al., 1987; Golovach et al., 2017). Transmembrane pore aperture results in the equilibration of $\mathrm{H}^{+}$across the inner membrane and the collapse of the $\mu \mathrm{H}^{+}$ gradient impairing the main function of mitochondria: ATP synthesis. The aim of this work was to explore the possibility that tamoxifen, through its antioxidant activity, could be a useful tool to offset the deleterious effects of disulfiram.

The experimental results indicate that Dis at the concentration of $7.5 \mu \mathrm{M}$ induced permeability transition characterized by the release of accumulated matrix $\mathrm{Ca}^{2+}$, collapse of the transmembrane electric gradient, membrane detachment of cytochrome $c$, and increased generation of hydrogen peroxide, as well as production of thiobarbituric acid reactive substances (TBARS). It should be noted that these effects are characteristic of oxidative stress, and were consequently inhibited by tamoxifen. 


\section{MATERIAL and METHODS}

Mitochondrial preparation and function analysis

Mitochondria were prepared by homogenizing tissue from kidney cortex in $250 \mathrm{mM}$ sucrose-1 mM EDTA adjusted to $\mathrm{pH} 7.3$, in a loose-fitting Teflon-glass homogenizer during $2 \mathrm{~min}$. Standard centrifugation procedure was then followed. Protein concentration was determined by the Lowry method (1951). Ca ${ }^{2+}$ movements were assayed spectrophotometrically at 675-685 $\mathrm{nm}$ using the metallochromic indicator Arsenazo III. Mitochondrial swelling was followed by changes in optical density at 540 $\mathrm{nm}$. Transmembrane electric gradient was determined at $527-575 \mathrm{~nm}$ by using the dye Safranine. Oxygen consumption was assayed by using a Clark-type electrode.

Aconitase activity

Aconitase activity was analyzed according to Hausladen and Fridovich (1994) as follows: mitochondrial protein was solubilized by adding $0.05 \%$ Triton X-100 containing $25 \mathrm{mM}$ phosphate, $\mathrm{pH} 7.2$ followed by the addition of 0.6 manganese chloride, $1 \mathrm{mM}$ citrate, and $0.1 \mathrm{mM}$ NADP. The formed cis-aconitate was measured spectrophotometrically at $240 \mathrm{~nm}$.

Analysis of superoxide dismutase activity 
Superoxide dismutase activity was determined in mitochondria by nondenaturating $8 \%$ acrylamide gel electrophoresis and nitro blue tetrazolium staining as described by Perez-Torres et al. (2009).

TBARS determination

Mitochondrial membrane lipid peroxidation was determined spectrophotometrically as the concentration of TBARS. A tetraethoxypropane curve was used as the standard.

Analysis of cytochrome c

Mitochondrial cytochrome c content was analyzed by western blot as follows: $15 \mu \mathrm{g}$ of mitochondrial protein was loaded onto $15 \%$ acrylamide SDS-PAGE gel and then transferred to a PVDF membrane for immunodetection. A primary monoclonal antibody against cytochrome c (1:1000 dilution) and a secondary alkaline phosphate conjugated antibody were used to evaluate the mitochondrial content of this enzyme.

Evaluation of hydrogen peroxide

The evaluation of $\mathrm{H}_{2} \mathrm{O}_{2}$ was carried out according to Dikalov et al. (2007) by incubating $2 \mathrm{mg}$ mitochondrial protein in $3 \mathrm{ml}$ of basic medium and 10 $\mu \mathrm{M}$ 10-acetyl-3, 7-dihydrophenoxazine plus $0.2 \mathrm{U} / \mathrm{ml}$ horse-radish peroxidase in a dark chamber at $37{ }^{\circ} \mathrm{C}$ during $60 \mathrm{~min}$. The resorufin 
produced was measured based on an increase in fluorescence at $530 \mathrm{~nm}$ excitation and 590 emission. Mitochondrial DNA disruption was analyzed in $0.8 \%$ agarose gel visualized by adding ethidium bromide. The genetic material was isolated from mitochondria as described by García et al. (2005).

Determination of sulfhydryl groups

Mitochondrial sulfhydryl groups were determined by using the reagent DTNB using cysteine as standard. The basic incubation mixture contained $250 \mathrm{mM}$ sucrose, $10 \mathrm{mM}$ succinate, $3 \mathrm{mM}$ phosphate, $10 \mathrm{mM}$ HEPES, 50 $\mu \mathrm{M} \mathrm{CaCl} 2,100 \mu \mathrm{M}$ ADP, $5 \mu \mathrm{g}$ rotenone, $2 \mu \mathrm{g}$ oligomycin. The medium was adjusted to $\mathrm{pH} 7.3$.

Labeling of adenine nucleotide carrier

To assess the effect of Dis on the labeling of the ADP/ATP carrier, $1 \mathrm{mg}$ mitochondria protein was suspended in $1 \mathrm{ml}$ of the basic medium and preincubated with $7.5 \mu \mathrm{M}$ Dis and $25 \mu \mathrm{M}$ tamoxifen during $5 \mathrm{~min}$, then 20 $\mathrm{nmol} / \mathrm{mg}$ protein of eosin-5-maleimide (EMA) was added (Majima et al., 1993) and incubated during $5 \mathrm{~min}$ at $4{ }^{\circ} \mathrm{C}$ in darkness. The reaction was stopped by the addition of $30 \mathrm{mM}$ DTTD. Mitochondria (300 $\mu \mathrm{g}$ protein) were then subjected to sodium dodecyl sulfate-polyacrylamide gel 
electrophoresis (SDS-PAGE) in 10\% polyacrylamide, under non-reduction conditions, and the fluorescence intensity was estimated with an UV lamp.

Analysis of aldehyde dehydrogenase activity.

The enzyme activity was assayed in a buffer containing $20 \mathrm{mM}$ sucrose, 10 M HEPES, $1 \mathrm{mM} \mathrm{EGTA}$, adjusted at pH 7.3. $05 \mathrm{mg}$ of mitochondrial protein was added to $3 \mathrm{ml}$ of the incubation mixture containing $0.04 \%$ of Triton $\mathrm{X}$ $100,1 \mu \mathrm{M}$ rotenone, and $1 \mathrm{mM}$ NAD. The reaction was initiated by the addition of $1 \mu \mathrm{M}$ propionaldehyde. The activity was followed fluoromtrically at $340 \mathrm{~nm}$ excitation and $460 \mathrm{~nm}$ emission. In addition the medium contained $10 \mu \mathrm{M}$ Dis and $25 \mu \mathrm{M}$ TAM.

\section{RESULTS}

It has been previously reported that the interaction of Dis with the mitochondrial membrane increases non-specific membrane permeability (Chavez et al., 1989; Balakirev and Zimmer 2001). In agreement with this, Fig. $1 \mathrm{~A}$ trace $\mathrm{i}$ illustrates that Dis at the concentration of $7.5 \mu \mathrm{M}$ induced the release of accumulated matrix $\mathrm{Ca}^{2+}$ through a mechanism likely involving the opening of the permeability transition pore. Trace ii reveals that after the addition of $25 \mu \mathrm{M}$ tamoxifen (TAM), Dis was unable to induce $\mathrm{Ca}^{2+}$ efflux. Trace iii depicts the control. Fig. 1B shows that the 
addition of $25 \mu \mathrm{M}$ tamoxifen reverts $\mathrm{Ca}^{2+}$ release reaction as induced by Dis; dashed line indicates that TAM was not added. However, when the reaction attained a fast efflux rate, TAM was not able to induce the reverse reaction (Fig. 1C). Fig. 1D illustrates that TAM does not affects the Ca2+ movement across the mitochondrial membrane, also it is indicated the protective effect of ascorbate and cyclosporine A (CSA)

Increased non-specific permeability is also mirrored as an increase in mitochondrial volume. Fig. 2 trace a shows that Dis addition induced a fast and large amplitude swelling; in contrast, trace b reveals that a marked inhibition of Dis-induced swelling occurred when the medium was supplemented with $25 \mu \mathrm{M}$ tamoxifen. Trace c illustrates the behavior of control mitochondria.

Analysis of the transmembrane electric gradient $(\Delta \Psi)$ is a useful tool for assessing both leakiness of the inner membrane after addition of disulfiram and its protection by tamoxifen. Figure $3 \mathrm{~A}$ illustrates that the addition of $7.5 \mu \mathrm{M}$ disulfiram induced a fast fall in $\Delta \Psi$. Nevertheless, as indicated in Fig. 3B, the addition of tamoxifen abolished the deleterious effect of Dis on the transmembrane potential. Nevertheless, as indicated the uncoupler CCCP collapsed totally the transmembrane electric gradient 
It has been reported that disulfiram affects mitochondrial oxygen consumption (Chávez et al., 1989; Kuroda and Cuellar, 1993). Thus, the effect of tamoxifen on Dis-induced oxygen consumption was explored with the aim to establish, whether or not, tamoxifen inhibits the effect of Dis. The findings indicated that in control conditions oxygen consumption shows a State 4 of respiratory rate of $427 \mathrm{nAO} / \mathrm{min} / \mathrm{mg}$ protein; this value was increased to $588.3 \mathrm{nAO} / \mathrm{min} / \mathrm{mg}$ protein after the addition of Dis. Nevertheless, after addition of tamoxifen the respiratory rate showed similar value to that observed in control mitochondria, i.e., 427.85 $\mathrm{nAO} / \mathrm{min} / \mathrm{mg}$ protein. Note that succinate was the oxidizing substrate.

It is conceivable that mitochondrial leakiness would be induced, in part, by oxidation of membrane polyunsaturated fatty acids. Hence, the resulting increase in the concentration of TBARS should be a useful parameter to estimate Disulfiram-induced oxidative stress (Lampka et al., 2006). As observed in Fig. 4, a higher amount of reactive species was generated by thiobarbituric acid in mitochondria treated with disulfiram. Interestingly, the concentration of TBARs was diminished by about $29 \%$ after tamoxifen treatment.

Aside from TBARS analysis, aconitase activity is a reliable marker for assessing damage to mitochondria by oxidative stress (Muller et al., 2004; 
Hernández-Esquivel et al., 2014). As illustrated in Table 1, the enzyme activity decreased by approximately $78 \%$ inhibition after the addition of disulfiram, i.e., from $365 \pm 10 \mathrm{nmol}$ aconitate $/ \mathrm{min} / \mathrm{mg}$ in control mitochondria to $83.2 \pm 4.3 \mathrm{nmol}$ aconitate $/ \mathrm{min} / \mathrm{mg}$. Indeed, a statistical significant protection by tamoxifen was observed, since the activity was reduced by only $10 \%$ (from $365 \pm 10 \mathrm{nmol} / \mathrm{min} / \mathrm{mg}$ to $351.31 \pm 12.1$ ).

Increased oxidative stress, induced by disulfiram in this work, could be linked to a decrease in the activity of the oxyradical-scavenging system. In tamoxifen-treated mitochondria, however, this decline in antioxidant activity would be avoided. To test this assumption, the activity of mitochondrial superoxide dismutase (SOD) was analyzed (Fig. 5). The value of SOD activity in mitochondria treated with disulfiram was remarkably around $40 \%$ of that observed in SOD activity of mitochondria treated with disulfiram plus tamoxifen $\left({ }^{*} p<0.05\right)$.

Previous reports indicate that permeability transition pore opening underlies cellular apoptosis (Gómez-Crisóstomo et al. 2013). To this regard, there is a growing body of evidence indicating the role of disulfiram treatment on the progression of the apoptotic mitochondrial pathway (Grosicka-Maciag et al., 2010; Hoda, e al., 2016), providing a mechanism for cytochrome $\mathrm{c}$ detachment from the cytosol side of the 
inner membrane. In this context, the level of cytochrome $\mathrm{c}$ in Dis-treated mitochondria and its protection with tamoxifen was explored. Certainly, as illustrated in Fig. 6 , there is a protein diminution of around $40 \%$ in the inner membrane of mitochondria treated with Dis. In addition, we observed that tamoxifen inhibited the release of the protein.

The generation of disulfiram-induced hydrogen peroxide and the inhibition by tamoxifen of this process were evaluated. As shown, the addition of Dis to mitochondria evoked a considerable increase of hydrogen peroxide (Fig. 7). This figure also shows that tamoxifen induced a significant inhibition.

Figure 8 illustrates the binding of the fluorescent reagent EMA to the adenine nucleotide translocase. It is must be stressed that after adding 7.5 $\mu \mathrm{M}$ disulfiram (Dis), the binding of the probe was diminished. This result seems to agree with the finding that disulfiram may block thiol groups (Dogterom et al., 1989). Regarding this, it is well known that there are a critical thiols groups in the translocase, which could be blocked by Dis, thus inhibiting the binding of the probe. Interestingly, the $-\mathrm{SH}$ groups were protected by tamoxifen, and so, they were able to be labeled by EMA. 
Figure 9 shows the effect of tamoxifen on the disulfiram-inhibition of mitochondrial aldehyde dehydrogenase. As is shown Dis inhibited the enzyme activity by around 50\%; it should be noted that the presence of tamoxifen did not abolish the inhibiting effect of disulfiram.

\section{DISCUSSION}

There is substantial evidence indicating the reactive effects of ROS, such as hydrogen peroxide, on the oxidative damage of membrane lipids and proteins (Grosicka-Maciag et al., 2010; Lushchak, 2015; Lee and Oe, 2016). As a result of such damage, a switch from specific to non-specific membrane permeability emerges (Halestrap et al., 1997; Pavón et al., 2014). Among the several manifestations of the so-called permeability transition are the increased efflux of $\mathrm{Ca}^{2+}$ and matrix metabolites, as well as the collapse of the transmembrane $\Delta \Psi$. Deleterious pleiotropic effects of oxidative stress are observed in numerous disease states and are implicated in a variety of drug-induced toxicities. Disulfiram has been implicated in oxidative cellular damage; this reagent exhibits strong electrophilicity that underlies its ability to react with protein cysteine residues (Van Gorp et al. 1997). In this context, it has been reported that inner membrane permeability is regulated by the redox status of thiol groups (Chávez et al., 1989). Accordingly, the amount of free sulfhydryl 
groups was estimated in the presence and absence of disulfiram and tamoxifen. It was surprising to find that the results indicated similar values, i. e., $34.6 \pm 6$ in control, $34.9 \pm 2$, plus Dis, and $37.2 \pm 6$ $\mathrm{nmol} / \mathrm{min} / \mathrm{mg}$ in mitochondria treated with Dis plus tamoxifen. However, the addition of Dis prevented the binding of eosin 5-maleimide (EMA) to adenine nucleotide translocase (ANT). As it has been documented (Majima et al., 1993), EMA interacts rapidly with $\mathrm{Cys}^{159}$; therefore, this cysteine residue may be the site of interaction with disulfiram.

Inhibition of permeability transition can be attained by different sort of reagents; indeed, immunosuppressant cyclosporine $A$ is the most effective. Tamoxifen has recently been identified as an effective inhibitor of membrane leakage (Custodio et al., 1998; Buelna-Chontal et al., 2016). Specifically, this compound is a selective estrogen receptor modulator widely used in the oncology and reproductive endocrinology (Birznice et al., 2010). Tamoxifen has also been demonstrated to possess antioxidant properties (Custodio et al., 1998; Buelna-Chontal et al., 2016). It is important to note that the protection obtained with tamoxifen on the pore-opening action of disulfiram presents relevant information on the mechanism involved. In particular, membrane leakage was induced by an elevation in the generation of ROS. This assumption emerges from the 
results in Figure 7, which point toward the Dis-induced augmented formation of hydrogen peroxide. Certainly, there exist many mechanisms that regulate the levels of ROS otherwise their reactive nature could cause cellular damage; among such mechanisms is the activity of the enzyme superoxide dismutase. However, when the cellular antioxidant capacity is exceeded, oxidative stress can ensue, which may occur after the inhibition of SOD by Dis (Fig. 7). The findings illustrated in Figure 4 show a characteristic response to membrane lipid oxidative stress. As demonstrated, there was a raised production of TBARs. Furthermore, Table 1 shows the inhibition of the enzyme aconitase by Dis; this effect can be for accounted by the fact that the enzyme contains a ROS-labile FeS cluster essential for its activity (Pandey et al., 2015). Note that the current results indicate that treatment with tamoxifen impeded the generation of $\mathrm{H}_{2} \mathrm{O}_{2}$, as well as lipid peroxidation and the oxidative inactivation of aconitase. Further, the significant capacity of tamoxifen to circumvent oxidative damage was demonstrated by inhibiting Dis-induced production of TBARS, as well as the oxidative-induced release of membrane-bound cytochrome c.

Conclusion: This work shows that tamoxifen prevents Dis-induced functional mitochondrial damage. Considering the results herein, it is 
tempting to propose the use of mitochondria-localizing antioxidants to prevent mitochondrial damage caused by drugs like disulfiram. 


\section{REFERENCES}

Amuchastegui, T., Amuchastegui, M., Donohue, T. 2014. Disulfiram alcohol reaction mimicking an acute coronary syndrome. Conn Med 78 (2): 81-84

Balakirev, M. Y., Zimmer, G. 2001. Mitochondrial injury by disulfiram: two different mechanisms of the mitochondrial permeability transition. Chem Biol. Interact. 138 (3): 299-311

Birzniece, V., Sata, A., Sutanto, S., Ho, K.K. 2010. Neuroendocrine regulation of growth hormone an androgen axes by selective estrogen receptor modulators in healthy men. J. Clin Endocrinol Metab. 95 (12): $5443-5448$

Buelna-Chontal, M., Hernández-Esquivel, L., Correa, F., Díaz-Ruiz J.L., Chávez, E. 2016. Tamoxifen inhibits mitochondrial oxidative stress damage by copper orthophenanthroline. Cell Biol. Int. 40 (12): 1349-1356

Cen, D., González, R. I., Buckmeier, J.A., Kahlon, RS., Tohidian, N.S., Meyskens, Jr., F.I. 2002. Disulfiram induces apoptosis in human melanoma cells: A redox-related process. Molecular Cancer Therapeutics 1(3): 197204, 
Chávez, E., Zazueta, C., Bravo, C. 1989. Extensive Ca2+ release from energized mitochondria induced by disulfiram. J. Bioenerg. Biomembr 21 (3): $335-345$

Chávez, E., Zazueta, C., Díaz, E., Holguín, J.A. 1989. Characterization by Hg2+ of two different pathways for mitochondrial Ca2+ release. Biochim. Biophys. Acta 986(1): 27-32

Crompton M., Costi, A., Hayat, L. 1987. Evidence for the presence of reversible Ca2+-dependent pore activated by oxidative stress in heart mitochondria. Biochem, J., 245 (3): 915-918

Custodio, J.B., Moreno, A.J., Wallace, K.B. 1998. Tamoxifen inhibits induction of the mitochondrial permeability transition by $\mathrm{Ca} 2+$ and inorganic phosphate. Toxicol Apples Pharmacol 152(1): 10-17

Dikalov, S., Griendlimg, K., Harrison, D.G. 2007. Measurement of reactive oxygen species in cardiovascular studies. Hypertension 49 (4): 717-727

Dogterom, P., Mulder, G. J., Fred Nagelkerke, J. 1989. Lipid peroxidationdependent and -independent protein thiol modifications in isolated rat hepatocytes: Differential effects of vitamin $E$ and disulfiram. Chemico Biological Interactions 71 (2-3): 291-306 
García, N., García, J.J., Correa, F., Chávez, E. 2005. The permeability transition pore as a pathway for the release of mitochondrial DNA. Life Sci. 76 (24): 2873-2880.

Golovach, N.G., Cheshchevic, V.T., Lapshina, E.A., Tillich, T.V., Zavodnick, I.B. 2017. Calcium-induced mitochondrial permeability transitions: Parameters of $\mathrm{Ca} 2+$ ions interactions with mitochondria and oxidative agents. J. Membr Biol. 250 (2): 225-236

Gómez-Crisosótomo, N.P., López-Marure, R., Zapata, E., Zazueta, C., Martínez-Abundis, E. 2013. Bax induces cytochrome c release by multiple mechanisms in mitochondria from MCF7 cells. J. Bioenerg. Biomembr. 45 (5): 441-448

Grosicka-Maciag, E., Kurpios-Piec, D., Gela, T., Crazed, H., Skrzycki, M., Szumilo, M., Rahdon,-Strain, I. 2010. Protective effect of Nacetyl-1cysteine against disulfiram-induced oxidative stress and apoptosis in V97 cells. Toxicology and Applied Pharmacology, 248 (3): 210-216

Halestrap, A.P., Woodfield, K.Y., Connern, C.P. 1997. Oxidative stress, thiol reagents, and membrane potential modulate the mitochondrial permeability transition by affecting nucleotide binding to the adenine nucleotide translocase. J. Biol. Chem. 272 (6): 3346-3354 
Hausladen, A., Fridovich, I. 1994. Superoxide and peroxynitrite inactive aconitases, but nitric oxide does not. J. Biol. Chem. 269 (47): 29405-29408

Hernández-Esquivel, L., Pavón, N., Buelna-Chontal, M., González-Pacheco, H., Belmont, J., Chávez, E. 2015. Cardioprotective properties of citicoline against hyperthyroidism-induced reperfusion damage in rat hearts. Biochem. Cell Biol. 93(3): 185-191

Hoda, M., Pajaniradje, S., Shalala, G., Mohankumar, K., Rajagopalan, R. 2016. Anti-proliferative and apoptosis-triggering potential of disulfiramloaded polysorbate 80 stabilized PLGA nanoparticles on hepatocellular carcinoma Hep3B cell line. Nanomedicine. 12(6): 1641-1650

Kuroda, M.A., Cuellar, A. 1993. Deleterious effects of disulfiram on the respiratory electron transport system of liver mitochondria. Int J. Biochem 25 (1): 87-91

Lampka M., Junik, R., Nowicka A, Kopczynska, E., Tyrakowki, T., OdrowazSypniewska, G. 2006. Oxidative stress markers during a course of hyperthyroidism. Endocrynol. Pol. 57 (3): 218-222.

Lee, S.H., Oe, T. 2016. Oxidative stress-mediated N-terminal protein modifications and MS-based approaches for N-terminal proteomics. Drug Metab. Pharmacokinet. 31(1): 27-34 
Majima, E., Koike, H., Hong, Y-M., Shinohara, Y., Terada, H. 1993. Characterization of cysteine residues of mitochondrial ADP/ATP carrier with the SH-reagents eosin 5-maleimide and N-ethylmaleimide. J. Biol Chem. 268 (29): 22181-22187

Muller, F.L., Liu, Y., Van Remmen, H. 2004. Complex III releases superoxide to both sides of the inner mitochondrial membrane. J. Biol. Chem. 279(47): 49064-49073

Pandey, A., Pain, J., Ghosh, A.K., Dancis, A., Pain, D. 2015. Fe-S cluster biogenesis in isolated mammalian mitochondria: coordinated use of persulfide sulfur and iron and requirements for GTP, NADH, and ATP. J. Biol. Chem. 290 (1): 640-657

Pavón, N., Hernández-Esquivel, L., Buelna-Chontal, M., Chávez, E. 2014 Antiarrhythmic effect of tamoxifen on the vulnerability induced by hyperthyroidism to heart ischemia/reperfusion damage. J. Steroid Biochem. Mol. Biol. 143: 416-423

Pérez-Torres I., Roque, P., El-Hafidi, M., Díaz-Díaz, E., Baños, G. 2009. Association of renal damage to oxidative stress in a rat model of metabolic syndrome influence of gender. Free Rad. Res 43(8): 761-771 
Santos, T., Martins-Campos A., Morais, H. 2016. Sensory motor axonal polyneuropathy involving cranial nerves: An uncommon manifestation of disuliram toxicity. Clin Neurol Neurosurgical. 152: 12-15

Tawari, P.E., Wang, Z., Najlah, M., Tsang, C.W., Aannappan, V., Liu, P., McConville, C., He, B., Drusilla, A.L., Wang, W. 2015. The cytotoxic mechanisms of disulfiram and copper (ii) in cancer cells. Toxicol Res. (Camb) 4 (6): 1439-1442

Van Gorp, R. M., Van Dam Mieras, M. C., Hornstra, G., Heemskerk, JW. 1997. Effect of membrane-permeable sulfhydryl reagents and depletion of glutathione on calcium mobilization in human platelets. Biochem. Pharmacol 53 (10): 1533-1542

Watts, T.E., Pandey, R.A., Vancil, T.J. 2014. Fatal fulminant hepatic failure to the use of disulfiram. J. Ark Med Sec 110 (13): 280-283 


\section{Figure Legends}

Fig. 1. Protective effect of tamoxifen. $\mathrm{Ca}^{2+}$ accumulation is maintained in kidney mitochondria after addition of disulfiram. Mitochondria $(2 \mathrm{mg}$ protein, M) were incubated in $3 \mathrm{ml}$ of a medium containing $250 \mathrm{mM}$ sucrose, $10 \mathrm{mM}$ succinate, $3 \mathrm{mM}$ phosphate, $100 \mu \mathrm{M}$ ADP, $50 \mu \mathrm{M} \mathrm{CaCl}$, 5 $\mu \mathrm{g}$ rotenone, $2 \mu \mathrm{g}$ oligomycin and $50 \mu \mathrm{M}$ Arsenazo III. In Panel A, trace a represents mitochondria after the addition of disulfiram (Dis). Trace $b$ depicts mitochondria treated with $7.5 \mu \mathrm{M}$ tamoxifen (TAM). Trace c indicates control mitochondria; where marked, $2.5 \mu \mathrm{M}$ disulfiram (Dis) was added. Where indicated in Panel B, $7.5 \mu \mathrm{M}$ disulfiram (Dis) and $25 \mu \mathrm{M}$ tamoxifen (TAM) were added. In Panel C, $7.5 \mu \mathrm{M}$ disulfiram (Dis) and 25 $\mu \mathrm{M}$ tamoxifen (TAM) were added. Final volume $3 \mathrm{ml}$, temperature $25^{\mathrm{e}} \mathrm{tc}$.

Fig. 2. Protective effect of tamoxifen against the disulfiram-induced mitochondrial swelling. Mitochondria (2 $\mathrm{mg}$ protein) were incubated in conditions similar to those described in Fig. 1, except that Arsenazo III was not added. Trace a illustrates mitochondrial behavior after the addition of $7.5 \mu \mathrm{M}$ disulfiram (Dis). Trace b depicts the protection against the effect of disulfiram after the addition of $25 \mu \mathrm{M}$ tamoxifen. Trace c shows control mitochondria. Where indicated, $50 \mu \mathrm{M} \mathrm{CaCl}_{2}$ was added. The traces are representatives of at least three different experiments 
Fig. 3. Protection of the disulfiram-induced collapse of transmembrane electric gradient by tamoxifen. Panel A shows the disulfiram (Dis) induced fall in $\Delta \Psi$. Panel B shows the protection induced by Tamoxifen (TAM). Incubation medium was similar to that described for Fig. 1, except that 10 $\mu \mathrm{M}$ Safranine was used instead of Arsenazo III. Where indicated, the following molecules and concentrations were used: $50 \mu \mathrm{M} \mathrm{Ca}{ }^{2+}, 7.5 \mu \mathrm{M}$ Dis, $25 \mu \mathrm{M}$ tamoxifen or $1 \mu \mathrm{M}$ CCCP.

Fig. 4. Evaluation of the protection induced by tamoxifen against the increased generation of TBARS found in mitochondria treated with disulfiram. The TBARS level was determined by incubation of $2 \mathrm{mg}$ of mitochondrial protein under conditions described in Materials and Methods. Where indicated, $7.5 \mu \mathrm{M}$ disulfiram (Dis) and/or $25 \mu \mathrm{M}$ tamoxifen (TAM) were added. The bars represent the average \pm SD of three different experiments ${ }^{*} p<0.05$

Fig. 5. Protection exerted by tamoxifen against the decrease in superoxide dismutase activity as induced by disulfiram. The bars represent the average $\pm S D$ of three separate experiments. ${ }^{*} \mathrm{P}<0.05$

Fig. 6. Protection by tamoxifen against the disulfiram-induced detachment of cytochrome $\mathrm{c}$ from the cytosol side of the inner membrane. Panel $A$ illustrates the western blot image of cytochrome $c$ retained in the 
mitochondrial inner membrane. Track $\mathrm{C}$ indicates the amount of cytochrome $\mathrm{c}$ in control mitochondria. The Dis tracks exhibit cytochrome c in mitochondria incubated in the presence of $7.5 \mu \mathrm{M}$ disulfiram, and Dis + TAM track illustrates cytochrome $\mathrm{c}$ in mitochondria incubated in the presence of $7.5 \mu \mathrm{M}$ disulfiram plus $25 \mu \mathrm{M}$ tamoxifen. The figure also shows a control containing only TAM. Panel B reveals the respective pixels from Panel A. The statistical significance was calculated using ANOVA and posttest Bonferroni per selected pairs. For all analysis, $\mathrm{p}<0.05$ was considered statistically significant. ${ }^{*} p<0.05$ vs control. ${ }^{*} p<0.05$ vs Dis. Adenine nucleotide translocase ANT was used as standard protein

Fig. 7. Attenuation of hydrogen peroxide generation by tamoxifen. Where indicated, mitochondria were incubated with either $7.5 \mu \mathrm{M}$ disulfiram or

$7.5 \mu \mathrm{M}$ Dis plus $25 \mu \mathrm{M}$ tamoxifen (TAM). The results are presented as the mean \pm SE of at least four different experiments. The statistical significance was calculated using ANOVA and post test Bonferroni for selected pairs. For analysis, $p<0.5$ was considered statistically significant. ${ }^{*} \mathrm{p}<0.05$ versus control. ${ }^{* *}<0.05$ versus disulfiram.

Fig. 8 Effect of tamoxifen on the disulfiram-inhibited labeling of the ADP/ATP translocase by EMA. $300 \mu \mathrm{g}$ of mitochondrial protein was subjected to SDS PAGE and fluorography. Where is indicated $7.5 \mu \mathrm{M}$ 
disulfiram (Dis) and $25 \mu \mathrm{M}$ tamoxifen (TAM) were added. SD and $p<0.05$ was considered statistically significant. Analysis was performed with the Prism 5.0 statistical package.

Fig. 9 Effect of tamoxifen on the disulfiram-inhibited the activity of mitochondrial aldehyde dehydrogenase enzyme. Where is indicated 10 $\mu \mathrm{M}$ disulfiram (Dis) and $25 \mu \mathrm{M}$ tamoxifen (TAM) were added. Data are the mean $\pm S D$ of three different experiments 


\section{$\underline{\text { Table } 1}$}

\section{Condition $\quad \underline{\mathrm{nmol} / \mathrm{min} / \mathrm{mg} \text { protein }}$}

\begin{tabular}{lr} 
Control & $365 \pm 10$ \\
TAM & $355 \pm 11.1$ \\
+ Dis* & $83.2 \pm 4.3$ \\
+ Dis + TAM & $351.31 \pm 4.3$ \\
\hline
\end{tabular}

Protective effect of tamoxifen against the deleterious effect of disulfiram on the cisaconitase enzyme in mitochondria. Where indicated disulfiram (Dis) and $25 \mu \mathrm{M}$ tamoxifen (TAM) were added $(n=4) . p \geq 0.005$ vs control 
Fig. 1
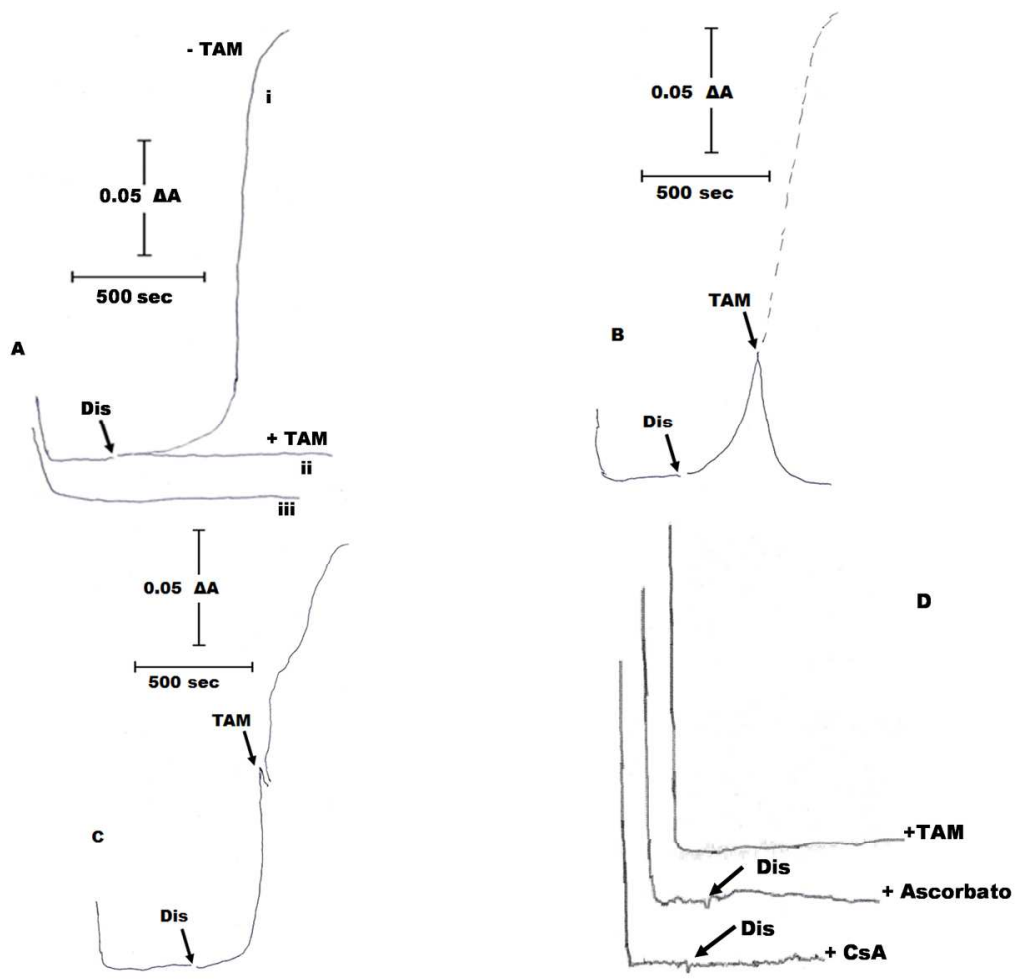

Fig. 1

$190 \times 142 \mathrm{~mm}(300 \times 300 \mathrm{DPI})$ 
Fig. 2

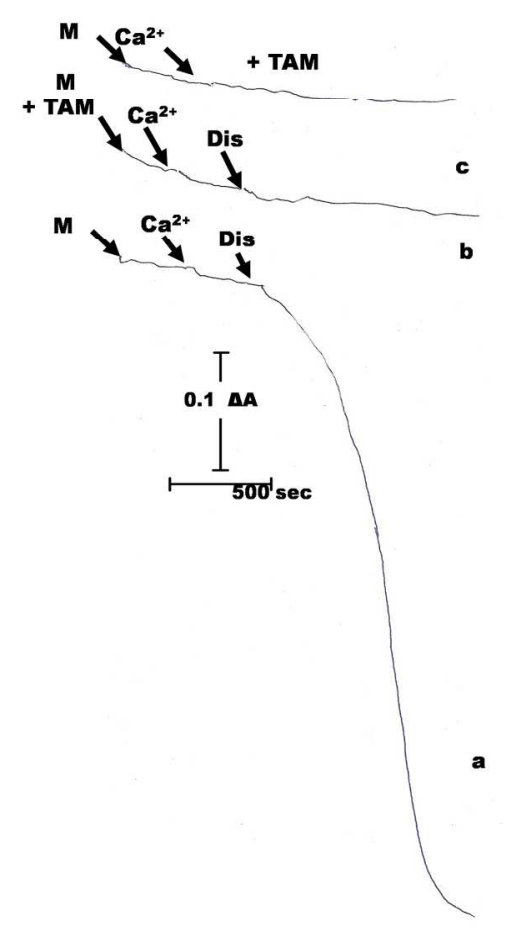

Fig. 2

$190 \times 142 \mathrm{~mm}(300 \times 300$ DPI $)$ 
Fig. 3

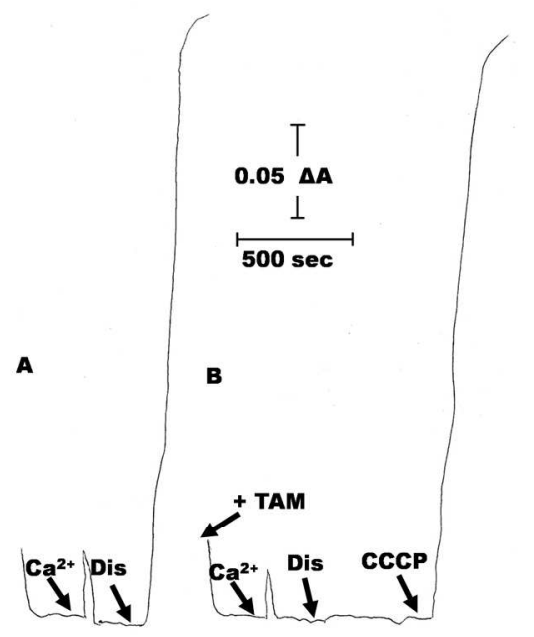

Fig. 3

$190 \times 142 \mathrm{~mm}(300 \times 300 \mathrm{DPI})$ 
Fig. 4

\section{TBARs}

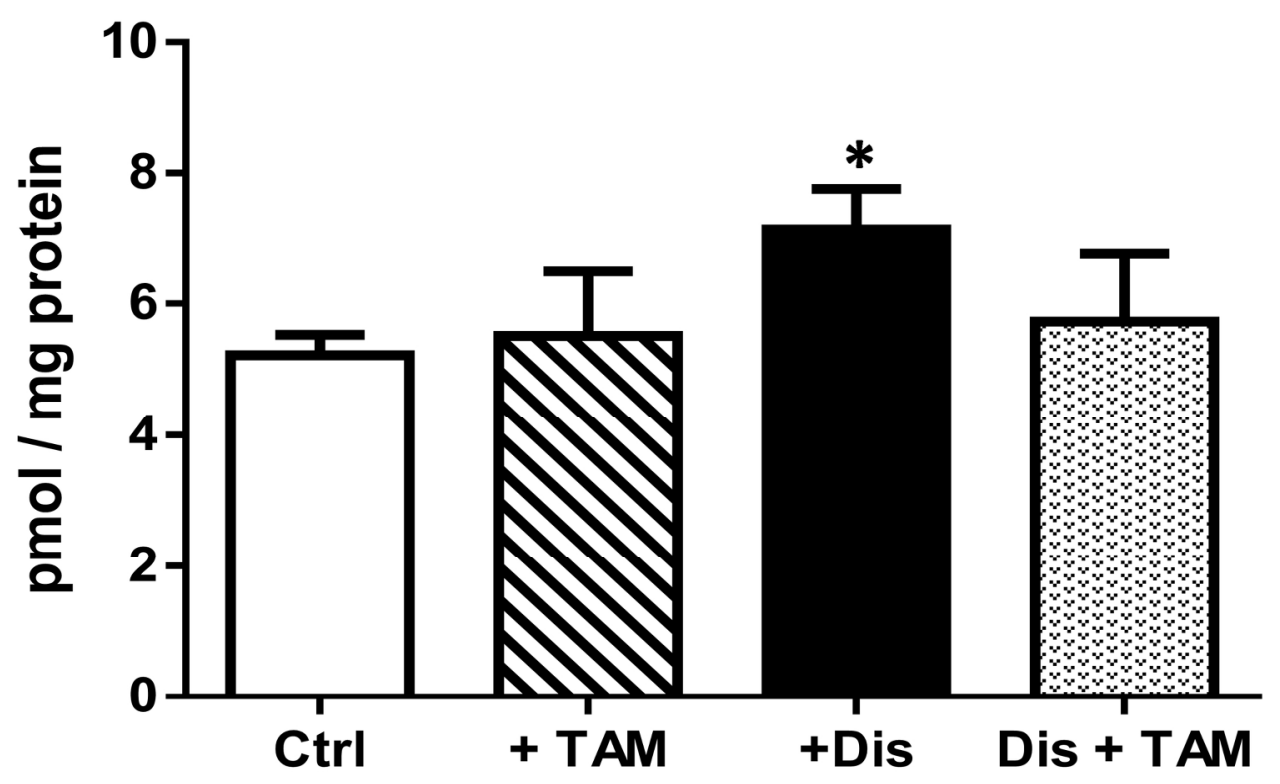

Fig. 4

$190 \times 142 \mathrm{~mm}(300 \times 300 \mathrm{DPI})$ 
Fig. 5

\section{SOD}

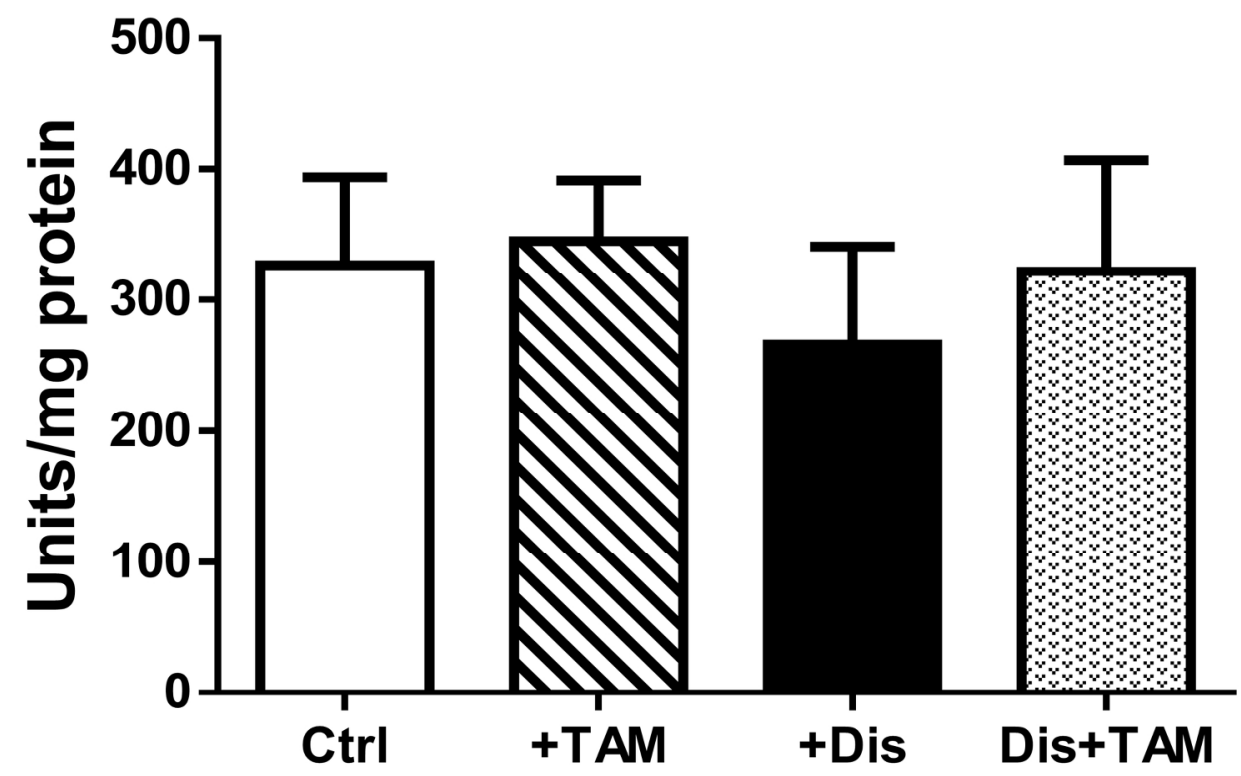

Fig. 5

$190 \times 142 \mathrm{~mm}(300 \times 300 \mathrm{DPI})$ 
Fig. 6
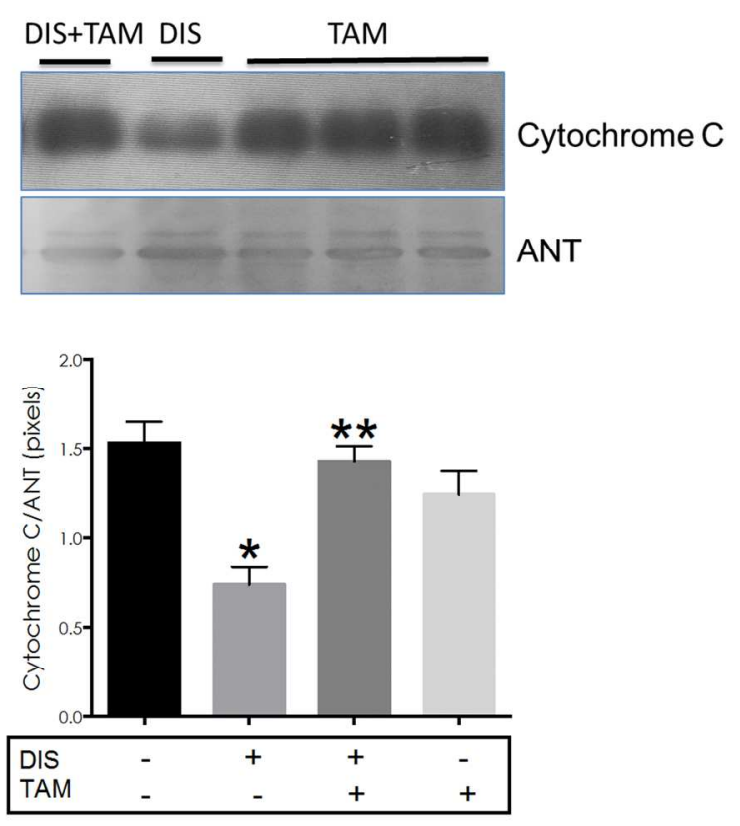

${ }^{*} \mathrm{P}<0.05$ vs. Control

${ }^{*} \mathrm{P}<0.05$ vs. DIS

Fig. 6

$190 \times 142 \mathrm{~mm}(300 \times 300 \mathrm{DPI})$ 
Fig. 7

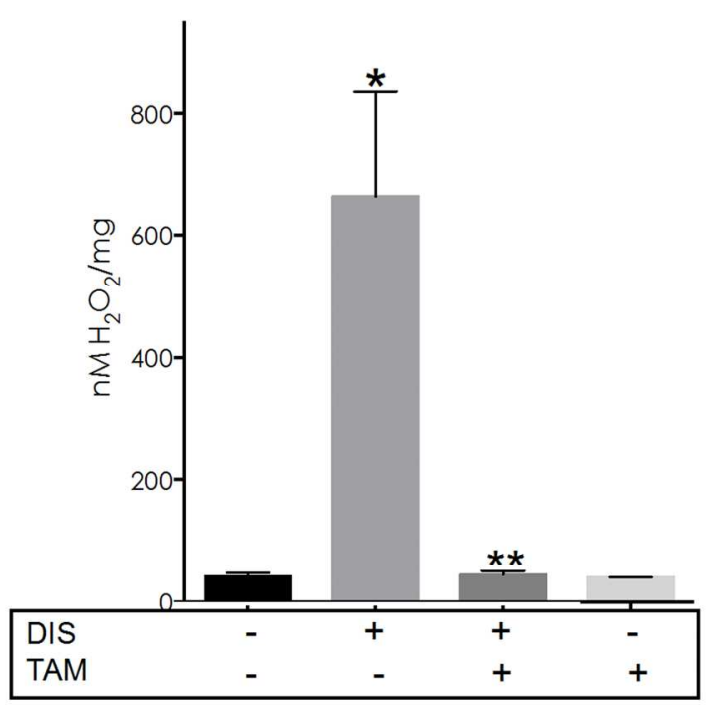

Fig. 7

$190 \times 142 \mathrm{~mm}(300 \times 300 \mathrm{DPI})$ 
Fig. 8
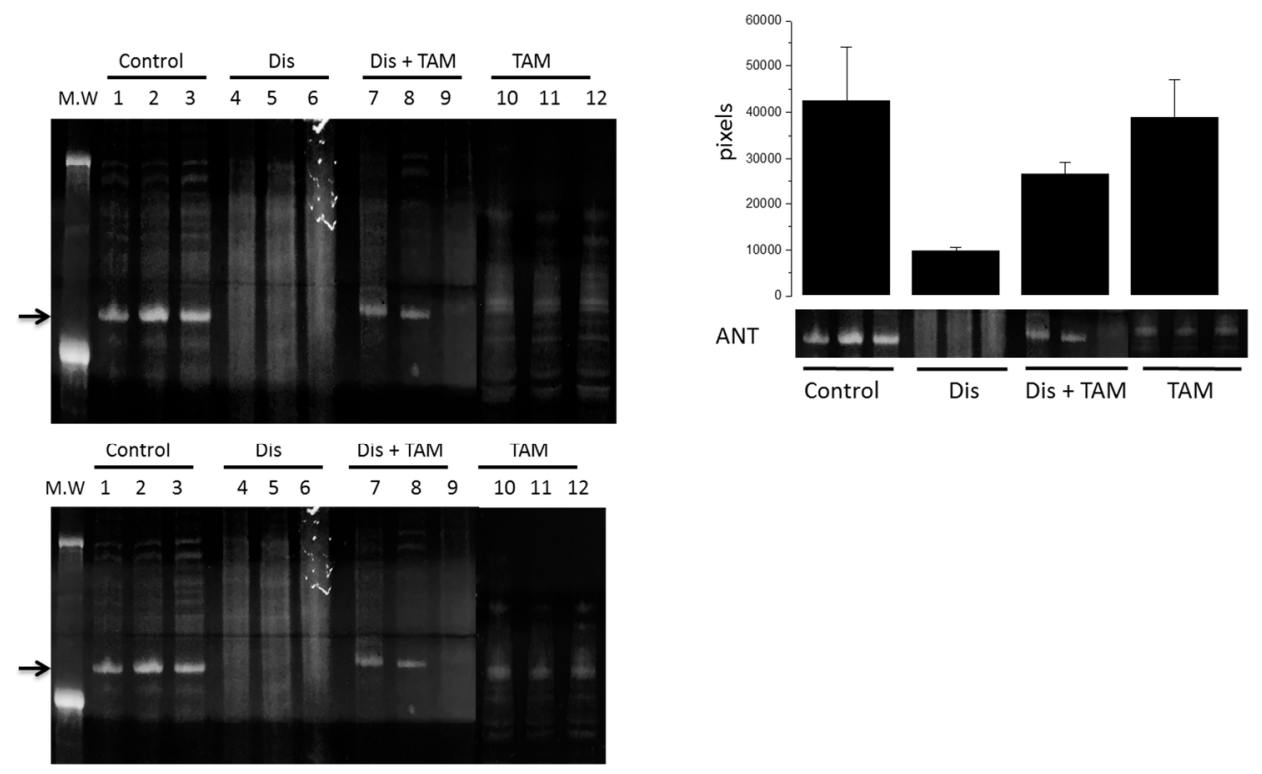

Fig. 8

$190 \times 142 \mathrm{~mm}(300 \times 300 \mathrm{DPI})$ 


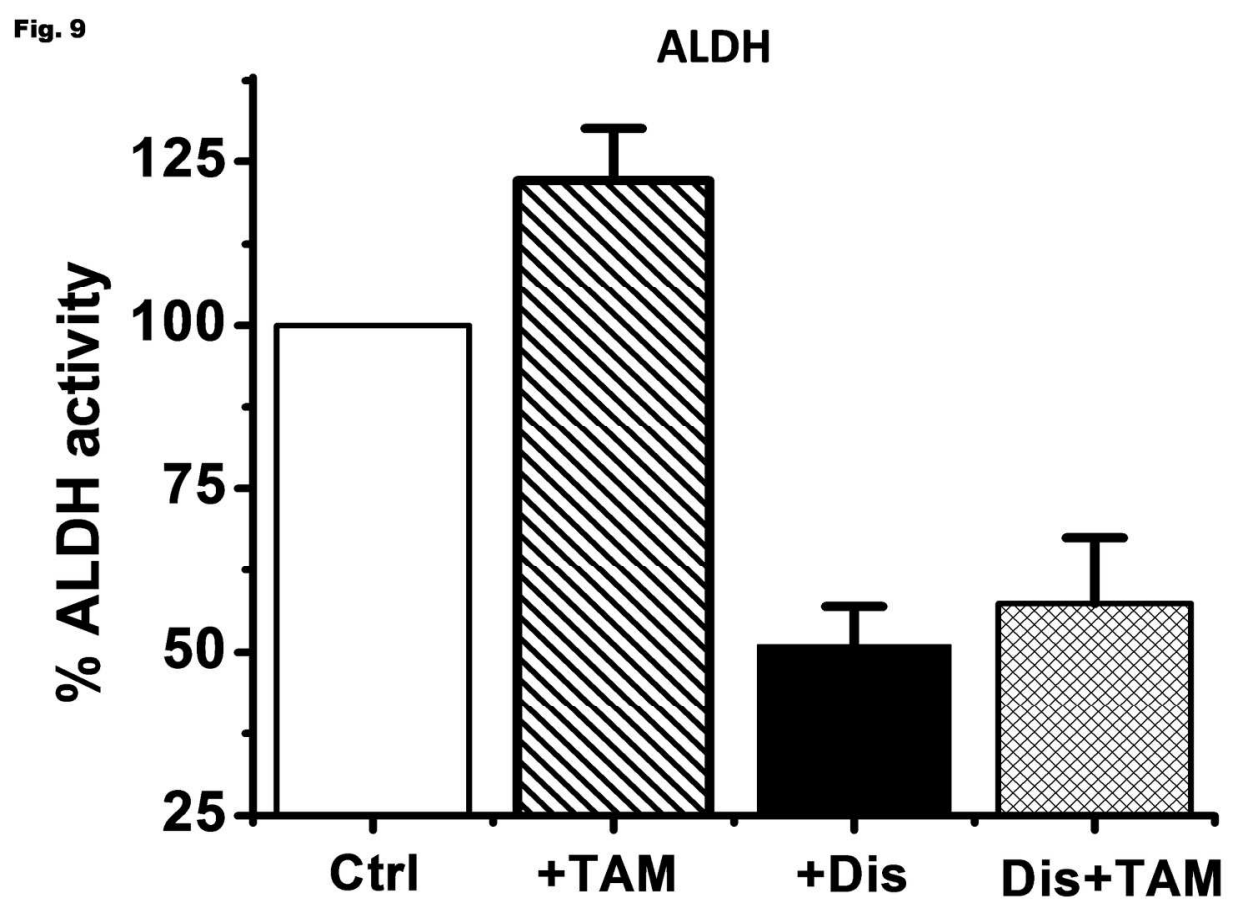

Fig. 9

$190 \times 142 \mathrm{~mm}(300 \times 300 \mathrm{DPI})$ 